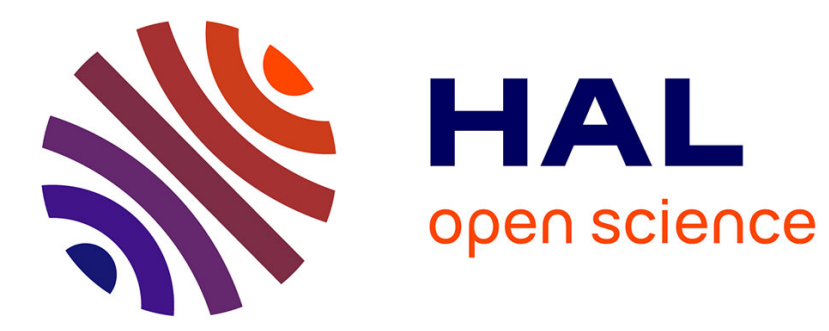

\title{
Parkinson's disease associated with 22q11.2 deletion: Clinical characteristics and response to treatment
}

Boris Dufournet, Karine Nguyen, Perrine Charles, David Grabli, Aurelia Jacquette, Michel Borg, Teodor Danaila, Eugénie Mutez, Sophie Drapier, Olivier Colin, et al.

\section{To cite this version:}

Boris Dufournet, Karine Nguyen, Perrine Charles, David Grabli, Aurelia Jacquette, et al.. Parkinson's disease associated with 22q11.2 deletion: Clinical characteristics and response to treatment. Revue Neurologique, 2017, 173 (6), pp.406-410. 10.1016/j.neurol.2017.03.021 . hal-01585889

HAL Id: hal-01585889

https://hal-univ-rennes1.archives-ouvertes.fr/hal-01585889

Submitted on 12 Oct 2017

HAL is a multi-disciplinary open access archive for the deposit and dissemination of scientific research documents, whether they are published or not. The documents may come from teaching and research institutions in France or abroad, or from public or private research centers.
L'archive ouverte pluridisciplinaire HAL, est destinée au dépôt et à la diffusion de documents scientifiques de niveau recherche, publiés ou non, émanant des établissements d'enseignement et de recherche français ou étrangers, des laboratoires publics ou privés. 


\section{Parkinson's disease associated with 22q11.2 deletion: Clinical characteristics and response to treatment.}

\section{Authors}

Boris Dufournet $(M D)^{a, b,{ }^{*}}$, Karine Nguyen $(M D, P h D)^{c, b}$, Perrine Charles $(M D, P h D)^{d, e}$, David Grabli (MD, PhD) $)^{\mathrm{f} e}$, Aurelia Jacquette $(M D)^{\mathrm{d}, \mathrm{e}}$, Michel Borg $(\mathrm{MD})^{\mathrm{g}}$, Teodor Danaila $(\mathrm{MD})^{\mathrm{h}, \mathrm{i}}$, Eugénie Mutez $(M D)^{\mathrm{j}, \mathrm{k}}$, Sophie Drapier (MD) ${ }^{1, \mathrm{~m}}$, Olivier Colin $(M D)^{\mathrm{n}, \mathrm{o}}$, Alexandre Eusebio (MD, $P h D)^{a, b}$, Nicole Philip (MD, PhD $)^{c, b}$, Jean Philippe Azulay (MD, PhD) ${ }^{a, b}$.

${ }^{a}$ Department of Clinical Neurosciences (Movement Disorders), Timone University Hospital (AP-HM), Marseille - France.

${ }^{\mathrm{b}}$ Aix-Marseille University, Marseille - France.

${ }^{\mathrm{c}}$ Department of Genetics (Neurogenetics), Timone University Hospital (AP-HM), Marseille - France.

${ }^{d}$ Department of Genetics (Neurogenetics), Pitié-Salpêtrière University Hospital (AP-HP), Paris - France.

${ }^{\text {e }}$ Sorbonne University, UPMC Paris 06 (UMR S 1127, CNRS UMR 7225, ICM), Paris - France.

${ }^{f}$ Department of Neurology (Movement Disorders), Pitié-Salpêtrière University Hospital (AP-HP), Paris France.

${ }^{\mathrm{g}}$ Department of Clinical Neurosciences (Movement Disorders), Nice University Hospital, Nice - France.

${ }^{\mathrm{h}}$ Department of Neurology (Movement Disorders), Pierre Wertheimer University Hospital (HCL), Lyon

- France.

' Lyon-1 University, Marc Jeannerod Center for Cognitives Neurosciences (CNRS UMR 5229), Lyon France.

${ }^{j}$ Department of Neurosciences (Movement Disorders), Lille University Hospital, Lille - France.

${ }^{k}$ Lille University (INSERM U1171), Lille - France.

' Department of Neurology (Movement Disorders), Rennes University Hospital, Rennes - France.

${ }^{\mathrm{m}}$ Rennes-1 University (URU 4712 « Basal Ganglia \& Behavior »), Rennes - France.

${ }^{n}$ Department of Neurology (Movement Disorders), Poitiers University Hospital, Poitiers - France. 
${ }^{\circ}$ Clinical Investigation Center (INSERM CIC 0802 \& INSERM U1084, Clinical and

Experimental Neurosciences), Poitiers University Hospital, Poitiers - France.

\section{*Corresponding author}

Dr. Boris Dufournet, CHU de La Timone (Assistance Publique - Hôpitaux de Marseille), 264 rue Saint Pierre, 13385 Marseille Cedex 5, France.

Tel.: +334 9138 4333; FAX: +334 9138 4336; E-mail adress: boris.dufournet@ap-hm.fr

\section{Word count}

For the paper (including titles): 1507; abstract (including titles): 160.

Character count for the title (including spaces): 105.

Number of references: 11, table: 1 and figure: 1.

\section{Declaration of interest.}

This study was not sponsored. The authors report no disclosures related to the manuscript.

\section{Funding}

This research did not receive any specific grant from funding agencies in the public, commercial, or not-for-profit sectors. 


\section{ABSTRACT}

Background. 22q11.2 microdeletions (22q11.2-del) increase the risk of Parkinson's disease (PD) but the characteristics of PD associated to 22q11.2-del have not been specifically explored.

Objective. To assess clinical and treatment-response characteristics, and to describe features that may lead a neurologist to investigate this comorbidity.

Methods. We report and describe 9 PD patients (8 men, 1 woman) followed in 7 centers of the French PD Expert Network (Ns-Park) also presenting the 22q11.2-del.

Results. PD diagnosis was made prior to 22q11.2-del diagnosis in 7 cases, the main characteristics are an early onset (32-48 y), a good initial DOPA-sensitivity but with a severe course characterized by severe and early-onset levodopa-induced motor complications and psychiatric manifestations. Three patients received deep-brain stimulation (DBS) with efficacy. Conclusions. Searching for 22q11.2-del in PD patients presenting suggestive features is relevant as the clinical presentation is close to idiopathic PD but with associated characteristics including a severe evolution. Results of DBS are similar to those reported in idiopathic PD.

\section{Key words}

Genetics; 22q11.2 Deletion Syndrome; Early Onset Parkinson's Disease; Phenotype; Deep Brain Stimulation. 


\section{Introduction}

The 22q11.2 deletion syndrome (22q11.2DS) [ICD10: D82.1; OMIM \#188400, \#192430], includes particularly moderate intellectual disability, facial dysmorphism, frequent psychotic disorders, conotruncal cardiopathy (77\%), velopalatine malformations ( $>75 \%)$, hypocalcaemia and immunodeficiency (75\%), concerns around $1 / 4000$ births [1-3] and the microdeletion (22q11.2-del) occurs de novo in 90\% of cases [2]. The 22q11.2DS, usually diagnosed in children, is exceptionally diagnosed in adults where it usually manifests as a long history of psychiatric disorders such as schizophrenia $[4,5]$. Some authors first reported co-occurrences of early onset Parkinson disease (EOPD) and 22q11.2DS [4,6-8] and searched for any molecular links $[6,9]$. Based on a few reports, an increased risk of EOPD has recently been suggested in 22q11.2DS [10] and confirmed in a recent article [11] where the authors reported the risk of EOPD conferred by deletions at 22q11.2 was about 20-times increased. However, the phenotypic features of this association remain to be systematically analyzed to assess clinical and treatment-response characteristics, and to describe features that may lead a neurologist to investigate this comorbidity.

\section{Methods}

\subsection{Subjects}

We collected all the established diagnosis of PD associated with 22q11.2-del in the 24 expert centers belonging to the French PD Expert Network (Ns-Park). Nine PD patients were reported (22q11.2-del was molecularly confirmed in all cases).

No systematic screening for the deletion was performed in this retrospective analysis.

Data were collected through a standardized questionnaire and concerned the characteristics 
of PD, the phenotypic pattern of 22q11.DS and the family history/genetics.

\subsection{Standard protocol approvals, registrations, and patient consents}

Informed consent was previously obtained from all patients for the genetic study. This study was approved by the local ethics committee.

\section{Results}

Eight men and 1 woman from 7 centers have been diagnosed and were currently followed at the time of the study. Their main characteristics are summarized in table 1.

\subsection{The PD phenotype}

PD diagnosis was made before 22q11.2DS diagnosis in 7 cases, at a mean age of 38 years [range: 32-48] and wasn't associated with any feature suggestive of atypical parkinsonism. All patients except 1 received levodopa with a significant motor effect. An acute levodopa test has been realized in 6 patients showing an improvement, with a mean UPDRS-III OFF score at 46 [SD: 19] and a mean UPDRS-III ON score at 16 [SD: 8].

Complications, including severe motor fluctuations and early-onset levodopa-induced peak-ofdose dyskinesia, developed in all patients on average 3.7 years [SD: 2.1 ] after disease onset. One patient developed a multiple impulse control disorder, 4 developed delusion and hallucinations under dopaminergic treatment that had not been reported before PD onset (DOPA-agonists in 2 cases and L-DOPA in 1 case). Axial involvement was present in 7 cases, with freezing of gait and falls in 4 cases, since 1 to 6 years from PD onset. Deep brain stimulation (DBS) was performed in 3 cases with a 30 to $70 \%$ improvement of the UPDRS-III motor score. 
Psychiatric symptoms are detailed below in "Phenotypic pattern of the 22q11.2DS". Two patients had their psychiatric symptoms treated with antipsychotic agents prior to PD onset (1 psychotic disorder and 1 severe social anxiety disorder). In both patients, evidence of dopaminergic denervation on DaTSCAN ${ }^{\circledast}$ was obtained (see below).

All patients were considered by clinicians presenting with an anterior mild intellectual disability, although only 1 patient was specifically tested with an Intellectual Quotient (IQ) test [total IQ: 54, Verbal IQ: 56, performance IQ: 55].

In 7 cases, a global neuropsychological assessment, realized after the diagnosis of PD and by a neuropsychologist, showed attentional and dysexecutive symptoms, but neither memory nor instrumental functions impairment.

The routine cognitive scales performed included the MDRS (in 7 cases), the MMSE score (in 5 cases) and the FAB score (in 5 cases). They respectively reached a mean of 128/144 [range: 119-137], 23/30 [21-25] and 11/18 [8-13].

Several non-motor symptoms were present in all cases, including hypersudation (4/9), constipation (6/9), diurnal somnolence (7/9), REM behavior disorder (4/8), urinary dysfunction (4/8), night or function cramps (5/8) and other pain (4/9). Restless leg syndrome was rare (1/9) and anosmia was never noted.

MRI imaging obtained in all patients showed no specific morphologic abnormality. DaTSCAN ${ }^{\circledR}$ was performed in 5 cases; all showed a presynaptic striatal denervation.

\subsection{Phenotypic pattern of the 22q11.2DS}

Facial dysmorphism was present and typical (figure A) in most patients (8/9), intellectual disability was constant - but mild as 6 patients could work in supported employment. Severe or recurrent respiratory infections in infancy were observed in 3 patients. Psychiatric symptoms preceded onset of PD and administration of levodopa and were constant: 
personality disorders (5/9), anxious symptoms (8/9, including social phobia in 2/9), depressive symptoms (5/9, but none had hypomanic or manic symptoms), irritability-dysphoria (5/9), apathy (6/9). Only 1 showed psychotic symptoms prior to levodopa.

\subsection{Family history and genetics}

The 22q11.2-del was molecularly confirmed by fluorescent in situ hybridization (FISH) in all cases. Two patients (cases 3 and 5) had a history of familial PD, with an affected first-degree relative, suggesting autosomal dominant inheritance. Genetic analysis of $L R R K 2$ was negative and family study for the 22q11.2DS wasn't performed, because the affected relatives died prematurely. The father of case 2 presented with tremor and cognitive impairment, but normal DaTSCAN excluded PD and, in accordance, LRRK2, SNCA were not mutated and 22q11.2-del was absent.

\section{Discussion}

We report herein the characteristics of 9 PD patients suffering from both 22q11.2DS and PD. Clinical data were obtained from PD Expert Centers, where PD patients were fully explored and cared for.

Mok et al. [11] recently highlighted the statistical relevance of this association, based on a genetic database. Eight patients with PD and none of the controls had 22q11.2-del. Mean age at PD onset was lower in 22q11.2-del patients than in controls (42.1 years [SD 11.9] versus 60.3 years [SD 12.8] respectively). A 22q11.2-del was present in more patients with earlyonset $(p<0.0001)$ and late-onset PD $(p=0.016)$ than in controls, and in more patients with early-onset than late-onset PD ( $p=0.005)$. 


\subsection{The PD phenotype}

PD diagnosis was made prior to 22q11.2DS diagnosis in 7 cases. The observed characteristics are compatible with idiopathic PD (IPD): absence of axial involvement and of significant cognitive deterioration at onset (at most mild and unspecific dysexecutive symptoms), while a mild and stable intellectual disability was present before the onset of the parkinsonian symptoms. The initial response to levodopa was excellent with a quantified DOPA-sensitivity superior to $50 \%$. Nevertheless, the evolution appeared severe with the occurrence of severe motor complications early in the course of the disease. Psychiatric symptoms were also frequent and seemed directly linked to dopaminergic treatment. In the Ns-Park Network, these patients were initially diagnosed as IPD, with an age of diagnosis ranging from 32 to 48 years (diagnosis before 40 years in 7/9), making these cases considered as early-onset PD (EOPD) and not juvenile parkinsonism explaining why genetic mutations such as Parkin or DJ1 were not screened. Additionally, the 22q11.2DS can be associated with hypoparathyroidism and calcifications of the basal ganglia, which were not observed in the present population and thus do not give an account of the parkinsonism, and Butcher et al. [10] provided 3 postmortem brain analysis that showed alpha-synuclein positive Lewy bodies (2/3), which is consistent with our findings. We can notice that REM behavior disorder was found in half of the patients. This element, usually encouraging neurologists to evoke a synucleinopathy as it is considered to be correlated with the presence of Lewy bodies, is not a usually reported symptom in other genetic young parkinsonisms and could thus be regarded as evocative of a 22q11.2-del.

\subsection{Phenotypic pattern of the 22q11.2DS}

In contrast, the 22q11.2DS appeared less severe in our series than classically described in children: all patients presented with mild features, especially none had cardiac malformations. 
This benign phenotype explains why those patients escaped from the diagnosis, which was delayed after the diagnosis of PD and likely why it is underestimated.

Interestingly, only one patient manifested psychotic symptoms before PD, conversely to the high frequency of schizophrenia (about 30\%) reported in literature [5].

Patients affected by the two conditions may carry a single, common genetic defect, as previously suggested $[6,9]$, leading to the consideration of PD as part of the phenotypic spectrum of 22q11.2DS, as suggested by Butcher et al. [10] and more recently by Mok et al. [11].

\subsection{Management of 22q11.2DS-associated PD patients}

As the described patients are DOPA-sensitive, they should be treated and managed as any IPD. The stage of motor complication should lead the clinician to adopt a classical strategy of management, i.e. pharmacological treatment adaptations and DBS, often required by the severity of the dopaminergic denervation (mean UPDRS-III OFF score at 46 [SD: 19]). The clinician needs to be aware of dopaminergic-induced psychiatric complications, as they appear to be quite frequent. They also could lead the neurologist to propose DBS in some cases to reduce dopaminergic treatment.

\section{Conclusion}

The neurologist involved in movement disorders would be more and more concerned by 22q11.2-del, as it is probably a new EOPD risk factor. We reported here the main characteristics of the parkinsonian features of such patients. 


\section{Acknowledgements}

List of the contributors from the Ns-Park/F-CRIN Network UMS 015 INSERM, FRANCE: Emmanuel

Broussole (MD, PhD), Jean-Luc Houeto (MD, PhD), Marie Vidailhet (MD, PhD), Luc Defebvre (MD, PhD), Isabelle Benatru (MD).

The authors thank Amy Patel (University of Bath, UK) for checking the English in the final version of the manuscript. 


\section{References}

[1] Online Mendelian Inheritance in Man, OMIM ${ }^{\circledR}$. OMIM Entry- \# 188400 - DIGEORGE SYNDROME, http://www.omim.org/entry/188400; 2016 [accessed 29.09.16].

[2] Orphanet. McDonald-McGinn DM, Zackai EH, 22q11.2 deletion syndrome, http://www.orpha.net/consor/cgi-bin/OC_Exp.php?Lng=FR\&Expert=567; 2012 [accessed 29.09.16]. [3] GeneReviews ${ }^{\circledR}$. McDonald-McGinn DM, Emanuel BS, Zackai EH, 22q11.2 Deletion Syndrome, https://www.ncbi.nlm.nih.gov/books/NBK1523/; 2013 [accessed 29.09.16].

[4] Krahn LE, Maraganore DM, Michels VV. Childhood-onset schizophrenia associated with parkinsonism in a patient with a microdeletion of chromosome 22. Mayo Clin Proc 1998;73:956-9.

[5] Bassett AS, Chow EWC. Schizophrenia and 22q11.2 Deletion Syndrome. Curr Psychiatry Rep 2008;10:148-57.

[6] Booij J, van Amelsvoort T, Boot E. Co-occurrence of early-onset Parkinson disease and 22q11.2 deletion syndrome: Potential role for dopamine transporter imaging. Am J Med Genet A 2010;152A:2937-8.

[7] Zaleski C, Bassett AS, Tam K, Shugar AL, Chow EWC, McPherson E. The co-occurrence of early onset Parkinson disease and 22q11.2 deletion syndrome. Am J Med Genet A 2009;149A:525-8.

[8] Boot E, Butcher NJ, Van Amelsvoort TAMJ, Lang AE, Marras C, Pondal M et al. Movement disorders and other motor abnormalities in adults with 22q11.2 deletion syndrome. Am J Med Genet A 2015;167A:639-45.

[9] Ogaki K, Ross OA. Chromosome 22q11.2 deletion may contain a locus for recessive early-onset Parkinson's disease. Parkinsonism Relat Disord 2014;20:945-6. 
[10] Butcher NJ, Kiehl T-R, Hazrati L-N, Chow EWC, Rogaeva E, Lang AE et al. Association between early-onset Parkinson disease and 22q11.2 deletion syndrome: identification of a novel genetic form of Parkinson disease and its clinical implications. JAMA Neurol 2013;70:1359-66.

[11] Mok KY, Sheerin U, Simón-Sánchez J, Salaka A, Chester L, Escott-Price V et al. Deletions at 22q11.2 in idiopathic Parkinson's disease: a combined analysis of genome-wide association data. Lancet Neurol 2016;15:585-96. 
Figure and Table legends
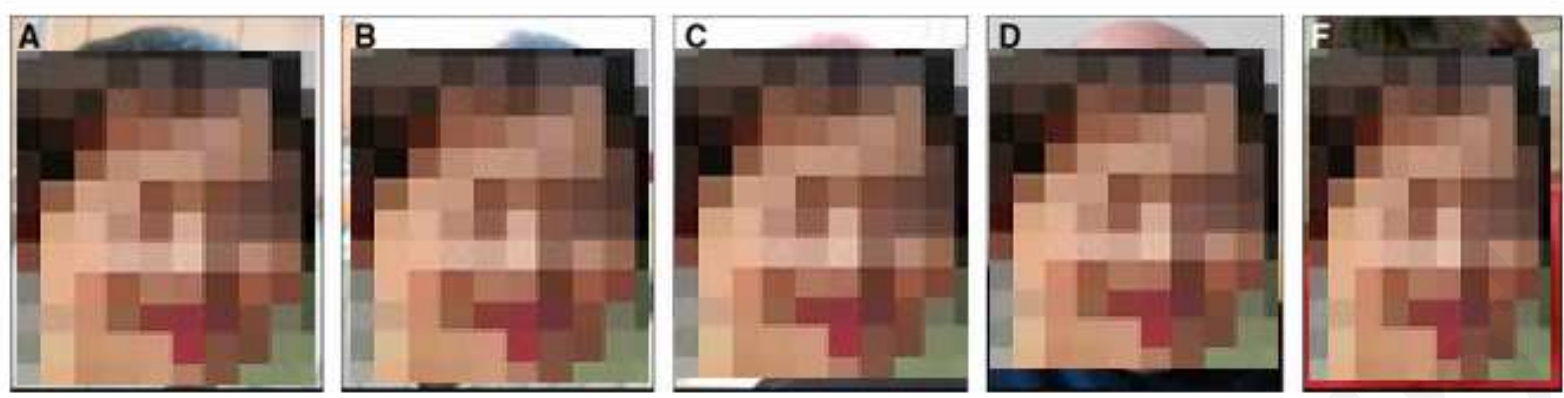

NOTE: photos have been removed from the author's manuscript for confidentiality reasons.

\section{Figure 1. Typical facial dysmorphism of 3 cases.}

Case $8(A, B)$, case $2(C, D)$ and case $1(E)$. One can observe long face, short philtrum, microtic ears that are low set and with lobule hypoplasia, broad nasal root, bulbous nasal tip and hypoplastic alae nasae. Telecanthus and ocular hypertelorism are not easily noticeable. 
Table 1: Main features of 22q.11.2DS and the associated PD of the 9 Ns-Park patients (individual data).

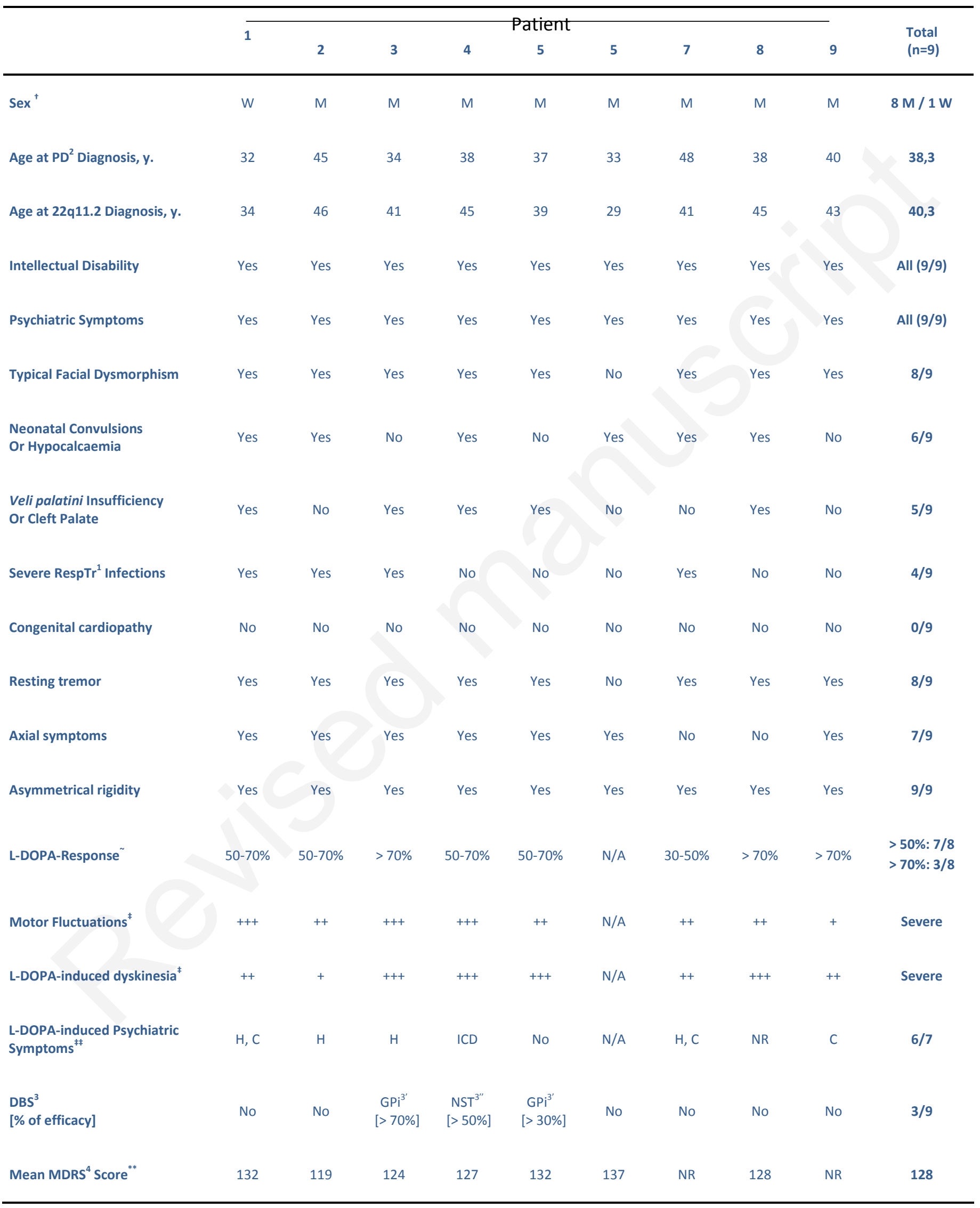


Legend: ${ }^{\dagger} M / W$, Men / Women; ${ }^{1}$ RespTr, Respiratory Tract; ${ }^{2} P D$, Parkinson's Disease; ${ }^{3} D B S$, Deep Brain Stimulation; ${ }^{4} M D R S$, Mattis Dementia Rating Scale; (Categories: $<30 \%$; 30-50\%; 50-70\%; >70\%); ${ }^{\ddagger}$ (intensity from 0 to +++ ); ${ }^{\# \neq} \boldsymbol{H}$ : hallucinations / C: confusion / N/A: not applicable / ICD: impulse control disorder / NR : not reported; GPi : internal Globus Pallidus; STN : subthalamic nucleus; ${ }^{* *}$ (score /144). 